\title{
Issues in Regional Economics: An Overview
}

\author{
Richard J. Cebula
}

(C) International Atlantic Economic Society 2015

This Special Issue consists of five studies. In the first of these, "Banks and Payday Lenders: Friends or Foes?" Barth, Hilliard, and Jahera observe that banks and payday lenders do not cater to the same customers. Banks typically serve moderately and higher income individuals as well as small and medium size enterprises. Payday lenders, on the other hand, typically serve lower income individuals. The biggest difference, however, given this difference in customers, is that payday lenders charge interest rates that are 30 to 80 times those charged by banks. This paper investigates the geographic distribution of payday lenders versus banks throughout the nation using county level data for all 50 states during the past decade, inclusive of the pre-crisis and post-crisis periods. The analysis takes into account differences in economic factors and demographic characteristics across the counties, permitting an assessment as to whether demographic characteristics are important determinants of the number of payday lenders relative to banks after taking into account economic factors. Moreover, the analysis examines the relationship between the number of payday lenders and community and smaller banks in counties to determine whether the geographical distribution of payday lenders versus banks is different for small banks as compared to big banks. Based upon the empirical findings, the paper discusses various policy options that may make credit available to lower income individuals at lower interest rates in contrast to the current situation.

In the study "Access to Higher Public Education and Locational Choices of Undocumented Migrants: An Exploratory Analysis," Cebula and Nair-Reichert note that many states have experienced a large influx of undocumented migrants in recent years. This phenomenon has created new demands on higher educational systems at the state level. Some states have passed legislation restricting the access of undocumented migrants to higher public education, whereas others provide increased access in various forms including in-state tuition. This research examines the impact of educational access on the location decisions of undocumented migrants in the U.S. It is found that undocumented migrants appear to locate in states with high average median real per capita incomes. There is also evidence of clustering of undocumented migrants in states with large migrant networks. However, the effect of educational access on the

R. J. Cebula ( $\triangle)$

Jacksonville University, Jacksonville, FL, USA

e-mail: rcebula@ju.edu 
percentage of undocumented workers in a state is mixed and small in most specifications, a finding perhaps indicative of a trade-off between competing priorities in the choice of location. The study "The Impact of Taxes, Community Fees, and Historic Designation on Single-Family Homes in Northeast Florida from 2008 to 2013," by Angjellari-Dajci, Boylan, Izard, and Gresham adopts a hedonic pricing model and a large dataset to investigate whether and to what extent increased property taxes and homeowners association (HOA) fees affected the real housing price of single-family homes from 2002 through 2013 in Duval County, Florida. The findings suggest that the prices of single-family homes in Duval County were negatively affected by real city and county property taxes but positively affected by membership in an HOA (and hence being subject to the associated real HOA fees). Regarding the effect of property taxes, the findings indicate that homeowners have been adversely impacted by a decline in their property values and hence in their wealth. By contrast, the value of membership in HOAs is positively capitalized into housing values for single-family homes. The authors hypothesize that the presence of HOA services and civic engagement yields a benefit that may permit the marginal benefits of HOA fees to exceed their marginal costs.

In the study "State Economic Freedom and Recidivism," Hall and Harger investigate the relationship between institutions and parolee recidivism rates for states in the U.S. Using a panel data set for the period 1994-2010, this study provides an exploratory analysis into what factors may contribute to differences across states in recidivism. The empirical results suggest, among other things, that higher levels of economic freedom within a state are associated with lower recidivism rates within that state, i.e., recidivism is a decreasing function of economic freedom.

Finally, in "The Effect of Military Base Closures on Rural County Economies: An Evaluation of the 1988-1995 Rounds of Cuts," Sorenson and Stenberg argue that recent announcements of a recommended downsizing of the U.S. Armed Forces, which are likely to include base closures, will bring a new focus on the effects of previous base realignments and closures (BRACs) on the economies of counties hosting military bases. This research provides a new analysis of the effects of base closures on counties which lost military bases or had significant losses due to realignment in the 1988 through 1995 rounds of military base restructuring. The study examines six counties which satisfied the criteria of experiencing a major loss of jobs and being located in non-metropolitan areas. The study employs a quasi-experimental methodology in which counter-factual control groups were selected to evaluate the effects of the base closures. Factors used in the procedure included several sectoral earnings percentages and income characteristics, growth rates in population and income, proximity to urban areas, population potential, and coefficients of specialization. Impact assessment uses the median growth rate among the control counties to calculate the expected employment by sector and year for the treated county. The expected employment value is then compared to actual employment to assess the impact by sector of the military base job loss. 